\title{
Enclosing the Air Gap from Formalin Delivery Tubing to Vertical-Flow Fish Egg Incubators Does Not Decrease Aerosolized Formaldehyde Levels
}

\author{
Jill M. Voorhees' ${ }^{1}$ Brian Fletcher ${ }^{2}$, Michael E. Barnes ${ }^{1 *}$ \\ ${ }^{1}$ South Dakota Department of Game, Fish and Parks, McNenny State Fish Hatchery, 19619 Trout Loop, Spearfish, South Dakota, \\ USA \\ ${ }^{2}$ South Dakota Department of Game, Fish and Parks, Cleghorn Springs State Fish Hatchery, 4725 Jackson Boulevard, Rapid City, \\ South Dakota, USA \\ Email: *mike.barnes@state.sd.us
}

How to cite this paper: Voorhees, J.M., Fletcher, B. and Barnes, M.E. (2018) Enclosing the Air Gap from Formalin Delivery Tubing to Vertical-Flow Fish Egg Incubators Does Not Decrease Aerosolized Formaldehyde Levels. Open Journal of Safety Science and Technology, 8, 98-105.

https://doi.org/10.4236/ojsst.2018.83006

Received: July 18, 2018

Accepted: September 4, 2018

Published: September 7, 2018

Copyright $\odot 2018$ by authors and Scientific Research Publishing Inc. This work is licensed under the Creative Commons Attribution International License (CC BY 4.0).

http://creativecommons.org/licenses/by/4.0/

\begin{abstract}
Formalin treatments are frequently used to control water molds during hatchery incubation of salmonid eggs, creating potential occupational safety and health issues. This investigation evaluated the use of a novel technique to enclose the air gap from formalin treatment tubes to 16-tray vertical-flow incubation stacks. Standard formalin treatments of $1667 \mathrm{mg} / \mathrm{L}$ for 15 -minutes were administered to one, three, or five stacks, both with, and without air gap enclosures. Enclosing the air gap did not significantly reduce aerosolized formaldehyde levels. Even during the treatment of five incubation stacks when formalin amounts were the greatest, mean (SE) peak airborne formaldehyde levels were $1.6(0.2) \mathrm{mg} / \mathrm{L}$ and $1.5(0.2) \mathrm{mg} / \mathrm{L}$, either with or without air gap enclosure, respectively. The failure of air gap enclosure indicates other techniques are required to decrease aerosolized formaldehyde during formalin treatments of fish eggs in vertical-flow incubators.
\end{abstract}

\section{Keywords}

Formalin, Formaldehyde, Incubation, Fish Eggs, Occupational Health

\section{Introduction}

Formalin is one of the most widely used therapeutic agents in fish culture [1], and consists of $37 \%$ formaldehyde and methanol in an aqueous solution. Depending on the source, formaldehyde is either a suspected [2] [3] or known [4] 
[5] [6] [7] human carcinogen. In the United States, formalin is approved for the control of external parasites on finfish or shrimp and for fungal control on finfish eggs [8].

Formalin is routinely used to control fungal (water mold) infections during the incubation of salmonid eggs [9], particularly when using vertical-flow incubators [10]. Such use can be potentially problematic for aquaculture workers. In a prior study, Voorhees and Barnes [11] found that the treatment of five vertical-flow incubation stacks produced airborne formaldehyde levels that exceeded permissible exposure level (PEL) of $2.0 \mathrm{ppm}$ set by the Occupational Safety and Health Administration (OSHA). While formalin can be delivered directly into the incubation water system with the proper technology, many hatcheries drip formalin into the top of the incubation stack from plastic tubing. To prevent back-flow siphon of water into the tubing, an air gap is required between the end of the tubing and the water in the incubation stack.

By providing an interface between formalin and the atmosphere, the air gap was hypothesized to contribute to formaldehyde aerosolization. Because no equipment currently exists to eliminate this air gap, a novel device was developed and described in this article. Additionally, its potential effects on airborne formaldehyde levels were evaluated.

\section{Methods}

\subsection{Study Location and Formalin Delivery}

The study was conducted at Cleghorn Springs State Fish Hatchery, Rapid City, $\mathrm{SD}$, USA, using $11^{\circ} \mathrm{C}$ spring water (total hardness as $\mathrm{CaCO}_{3}, 36 \mathrm{mg} / \mathrm{L}$; alkalinity as $\mathrm{CaCO}_{3}, 210 \mathrm{mg} / \mathrm{L} ; \mathrm{pH}, 7.6$; total dissolved solids, $390 \mathrm{mg} / \mathrm{L}$ ). Formalin (Parasite-S; 37\% formaldehyde, 6\% - 14\% methanol; Syndel USA, Ferndale, Washington) was administered to vertical-flow incubators (MariSource, Fife, Washington) using a peristaltic pump (Masterflex model 07524-40 pump driver; 07519-25 pump head; cartridge model 07519-85; Cole-Parmer Instrument Company, Vernon Hills, Illinois). Each incubation stack of 16 trays received $11.34 \mathrm{~L} / \mathrm{min}$ of constant water flow. Formalin treatments were set at $1667 \mathrm{mg} / \mathrm{L}$ for 15 minutes [1]. Figure 1 illustrates the experimental incubation stack design.

\subsection{Air Gap Elimination Device}

In order to prevent the back siphon of water from the incubation stack into the formalin reservoir, the formalin was not injected directly into the water. Rather, there was a gap between the end of the tubing ( $2.4 \mathrm{~mm}$ i.d.; C-Flex; Cole-Parmer Instrument Company, Vernon Hills, Illinois) coming from the peristaltic pump and the uppermost incubation tray (Figure 2) in the control treatment. This air gap was eliminated in the experimental treatment by modifying a $15 \mathrm{~mL}$ polypropylene centrifuge tube (Labcon, Petaluma, California, USA). A hole was drilled in the closed end of the centrifuge tube, into which was inserted the flexible tubing. The cap was removed from the centrifuge tube, and this end of the tube was placed in the incubation water (Figure 3). 


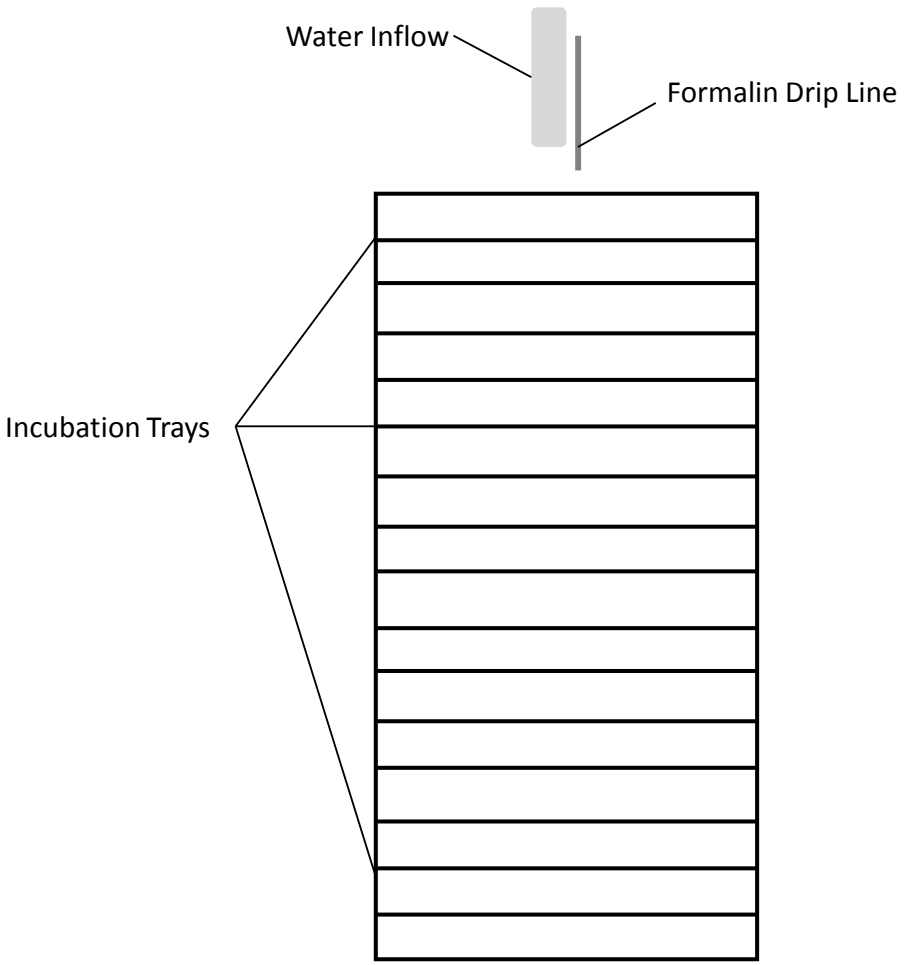

Figure 1. Illustration of the water inlet, formalin drip line tubing, and sixteen tray incubation stack.
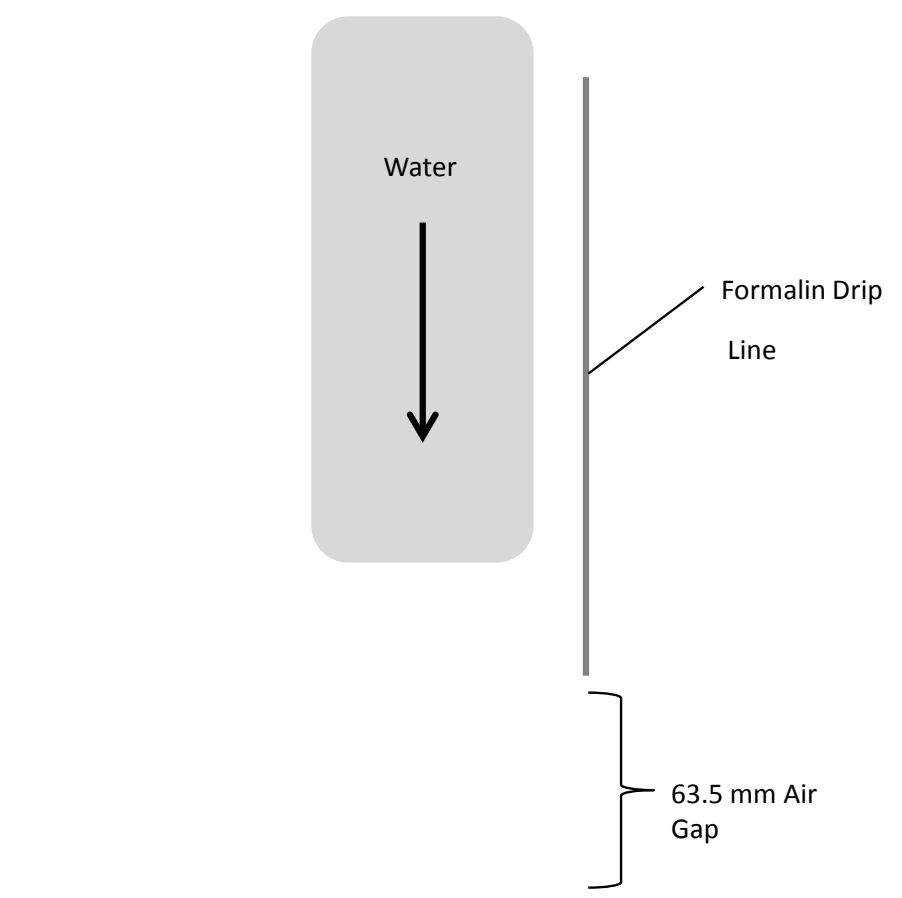

Top Tray

Figure 2. Diagram of formalin dispensing location into vertical-flow egg incubation stack. 


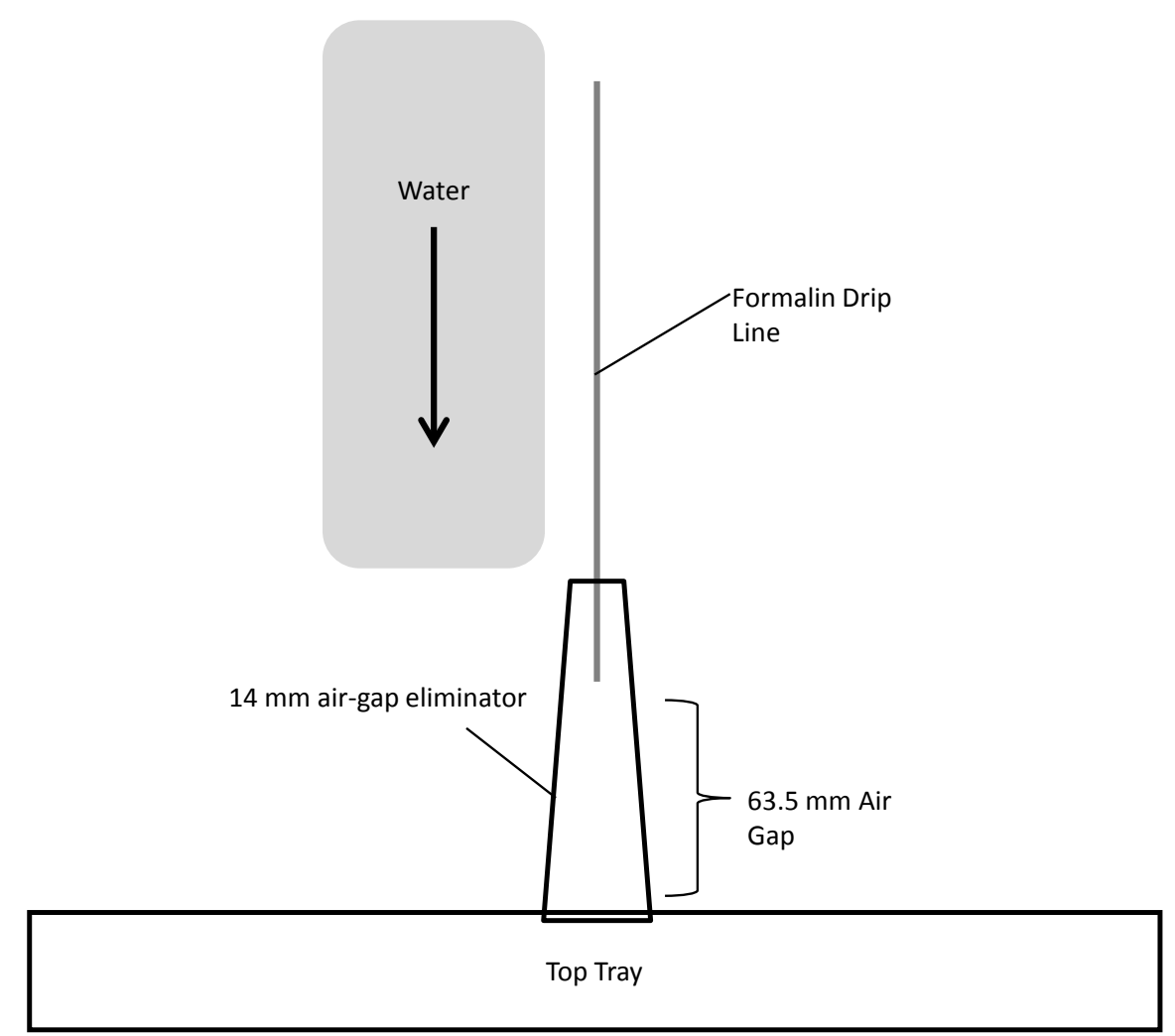

Figure 3. Diagram of modified centrifuge tube used during formalin treatment into vertical-flow egg incubation stack.

\subsection{Evaluation Experimental Design}

The incubation room contained five sixteen-tray stacks and five eight-tray stacks (Figure 4). Throughout the experiment, water was continuously supplied to all ten stacks to ensure high and constant humidity for consistent airborne formaldehyde measurement [12] [13]. Airborne formaldehyde concentrations were measured in six trials, which varied in the number of 16-tray incubation stacks treated (one, three, or five) and if the air gap was eliminated (Table 1). The door to the small closet containing the exhaust fan was left open throughout all of the trials. Each trial was replicated three times.

Airborne formalin concentrations were measured using a formaldehyde meter (model HAL-HFX2051; HalTech; Fontana, California). Prior to any trials, basal formalin concentrations were measured and consistently found to be $0.2 \mathrm{mg} / \mathrm{L}$. During the trials, formalin measurements were recorded every min for the first 60 min after the start of a treatment. If the concentration was at the basal concentration after the first $60 \mathrm{~min}$, no further formalin readings were conducted. However, if the values were elevated above the basal level, additional readings were taken thereafter at $30 \mathrm{~min}$ intervals until basal readings were obtained.

Formaldehyde concentrations were compared to the United States Department of Labor, Occupational Safety and Health Administration (OSHA) regulation limits of $0.75 \mathrm{mg} / \mathrm{L}$ permissible exposure limit (PEL) measured as an 8-hour 
Table 1. Description of experimental design, including number of vertical-flow incubators evaluated in each trial, along with the use of test tube.

\begin{tabular}{ccc}
\hline Trial & Number of Stacks & Use of Test Tube \\
\hline 1 & 1 & yes \\
2 & 1 & no \\
3 & 3 & yes \\
4 & 3 & no \\
5 & 5 & yes \\
6 & 5 & no \\
\hline
\end{tabular}

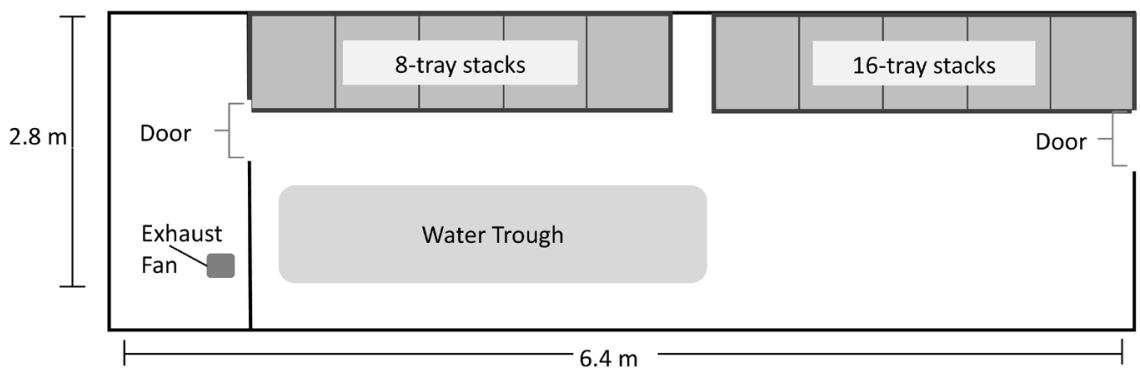

Figure 4. Diagram of incubation room.

time-weighted average (TWA), and the $2.0 \mathrm{mg} / \mathrm{L}$ short-term exposure limit (STEL) as measured in a 15-minute period, and the OSHA action level of 5.0 mg/L TWA [2].

\subsection{Statistical Analysis}

Data were analyzed using the SPSS (9.0) statistical analysis program (SPSS, Chicago, Illinois). Statistical significance was predetermined at $p<0.05$. Two-way ANOVA was used for analysis.

\section{Results}

The use of the air-gap eliminator had no significant effect on any of the parameters measured (Table 2). The time (minutes) it took to reach peak formaldehyde levels, the peak of formaldehyde reached, the time (minutes) to reach PEL, the time (minutes) the level stayed above PEL, and the time (minutes) to get back to the base level were similar between the groups. Even with the use of the modified centrifuge tubes, and regardless the number of incubation stacks being used, the OSHA [2] action level was still reached in the all trials. Back-feeding (siphoning) of water from the incubation stack into the formalin barrel when the air gap eliminator was being used was also observed.

\section{Discussion}

\subsection{Device Effectiveness}

Obviously, eliminating the formalin treatment tubing air gap had no effect on 
Table 2. Mean $( \pm$ SE) parameters measured for 1,3 , or 5 stacks being treated simultaneously.

\begin{tabular}{|c|c|c|c|}
\hline \multirow{2}{*}{$\begin{array}{c}\text { Number of } \\
\text { Stacks }\end{array}$} & \multirow{2}{*}{ Measurement } & \multicolumn{2}{|c|}{ Use of Test Tube } \\
\hline & & Yes & No \\
\hline \multirow[t]{5}{*}{1} & Time to peak formaldehyde levels (min) & $28.5 \pm 4.2$ & $22.5 \pm 2.5$ \\
\hline & Peak formaldehyde levels (mg/L) & $0.4 \pm 0.0$ & $0.5 \pm 0.0$ \\
\hline & Time to reach above PEL $^{1}$ & $0.0 \pm 0.0$ & $0.0 \pm 0.0$ \\
\hline & Time above PEL & $0.0 \pm 0.0$ & $0.0 \pm 0.0$ \\
\hline & Time back to base & $52.0 \pm 3.3$ & $49.3 \pm 3.2$ \\
\hline \multirow[t]{5}{*}{3} & Time to peak formaldehyde levels & $25.0 \pm 2.7$ & $25.3 \pm 2.3$ \\
\hline & Peak formaldehyde levels & $1.2 \pm 0.1$ & $1.0 \pm 0.1$ \\
\hline & Time to reach above PEL & $16.2 \pm 1.9$ & $12.5 \pm 4.2$ \\
\hline & Time above PEL & $19.2 \pm 2.2$ & $12.3 \pm 4.1$ \\
\hline & Time back to base & $62.0 \pm 3.4$ & $62.5 \pm 0.8$ \\
\hline \multirow[t]{5}{*}{5} & Time to peak formaldehyde levels & $24.5 \pm 2.8$ & $25.7 \pm 2.2$ \\
\hline & Peak formaldehyde levels & $1.6 \pm 0.2$ & $1.5 \pm 0.2$ \\
\hline & Time to reach above PEL & $14.0 \pm 1.4$ & $14.0 \pm 2.4$ \\
\hline & Time above PEL & $27.2 \pm 2.7$ & $24.2 \pm 3.8$ \\
\hline & Time back to base & $77.3 \pm 14.1$ & $84.7 \pm 5.1$ \\
\hline
\end{tabular}

${ }^{1}$ Permissible Exposure Level $=$ PEL .

aerosolized formaldehyde levels in this study. These results indicate that most of the formaldehyde aerosolization is likely occurring due to surface deposition as the water falls from each incubation tray into the tray immediately below it [14]. The small air gap from the formalin tubing to the incubation stack water surface appears to be a very minor contributor to formaldehyde aerosolization.

\subsection{Back Flow Issues}

The back-flow of water from the incubation stack into the barrel of formalin used for egg treatment was unexpected and also very problematic. It is possible that if such back-feeding occurred during actual production-level formalin treatments, that it might not be detected, resulting in a dilution of the source formalin. Treatment at lower formalin concentrations may be ineffective at egg fungal control [15]. Even more problematic would be if such back-feeding resulted in formalin discharge from the source barrel, resulting in additional occupational exposure during the clean-up and remediation of the spill [16] [17].

\section{Conclusion}

The novel air-gap elimination device described in this study was ineffective at reducing airborne formaldehyde levels. Thus, further experimentation is needed to find ways to reduce the occupational exposure of aquaculture workers to for- 
maldehyde during routine egg treatments. Although potentially disconcerting, the publication of negative results is also encouraged to prevent study duplication and promote learning [18] [19] [20].

\section{Acknowledgements}

We thank Cody Treft and Tabor Martin for their assistance with this study.

\section{Conflicts of Interest}

The authors declare no conflicts of interest regarding the publication of this paper.

\section{References}

[1] Piper, R.G., McElwain, I.B., Orme, L.E., McCraren, J.P., Fowler, L.G. and Leonard, J.R. (1982) Fish Hatchery Management. 4th Printing, U.S. Fish and Wildlife Service, Washington, DC.

[2] OSHA (Occupational Safety and Health Administration) (2011) OSHA Fact Sheet. United States Department of Labor.

https://www.osha.gov/OshDoc/data_General_Facts/formaldehyde-factsheet.pdf

[3] NIOSH (National Institute of Occupational Safety and Health) (2016) NIOSH Pocket Guide to Chemical Hazards: Formaldehyde. Centers for Disease Control. https://www.cdc.gov/niosh/npg/npgd0293.html

[4] IARC (International Agency for Research on Cancer) (2011) Formaldehyde. World Health Organization.

http://monographs.iarc.fr/ENG/Monographs/vol100F/mono100F-29.pdf

[5] ATSDR (Agency for Toxic Substances and Disease Registry) (2015) Formaldehyde-ToxFAQs. Department of Health and Human Services. http://www.atsdr.cdc.gov/toxfaqs/tfacts111.pdf

[6] New Jersey Department of Health (2016) Right to Know: Hazardous Substance Fact Sheet: Formaldehyde. http://nj.gov/health/eoh/rtkweb/documents/fs/0946.pdf

[7] National Toxicology Program (2016) 14th Report on Carcinogens. U.S. Department of Health and Human Services.

https://ntp.niehs.nih.gov/pubhealth/roc/index-1.html\#toc1

[8] FDA (United States Food and Drug Administration) (2018) Approved Aquaculture Drugs. U.S. Department of Health and Human Services.

https://www.fda.gov/AnimalVeterinary/DevelopmentApprovalProcess/Aquaculture /ucm132954.htm

[9] Barnes, M.E., Cordes, R.J. and Sayler, W.A. (1997) Use of Formalin During Incubation of Eyed Eggs of Inland Fall Chinook Salmon. The Progressive Fish-Culturist, 59, 303-306. https://doi.org/10.1577/1548-8640(1997)059<0303:UOFDIO>2.3.CO;2

[10] Stickney, R.R. (1994) Principles of Aquaculture. John Wiley \& Sons, New York.

[11] Voorhees, J.M. and Barnes, M.E. (2016) Airborne Formaldehyde Levels During Simulated Formalin Egg Treatments in Vertical-Flow Tray Incubators at a Production Fish Hatchery. Journal of Agriculture Safety and Health, 22, 199-207. https://doi.org/10.13031/jash.22.11791

[12] Kennedy, E.R. and Hull, R.D. (1986) Evaluation of the Du Pont Pro-Tek Formaldehyde Badge and the 3M Formaldehyde Monitor. American Industrial Hygiene and Association Journal, 47, 94-105. https://doi.org/10.1080/15298668691389414 
[13] Obee, T.N. and Brown, R.T. (1995) $\mathrm{TiO}_{2}$ Photocatalysis for Indoor Air Applications: Effects of Humidity and Trace Contaminant Levels on the Oxidation Rates of Formaldehyde, Toluene, and 1,3-Butadiene. Environmental Science \& Technology, 29, 1223-1231. https://doi.org/10.1021/es00005a013

[14] Nazaroff, W.W. and Cass, G.R. (1989) Mathematical Modeling of Indoor Aerosol Dynamics. Environmental Science and Technology, 23, 157-166. https://doi.org/10.1021/es00179a003

[15] Barnes, M.E. and Soupir, C.A. (2006) Evaluation of Formalin and Hydrogen-Peroxide Treatment Regimes on Rainbow Trout Eyed Eggs. North American Journal of Aquaculture, 69, 5-10. https://doi.org/10.1577/A05-080.1

[16] Burgess, J.L. (1999) Hospital Evacuations Due to Hazardous Materials Incidents. American Journal of Emergency Medicine, 17, 50-52.

https://doi.org/10.1016/S0735-6757(99)90016-5

[17] Hill Jr., R.H. and Finster, D.C. (2013) Academic Leaders Create Strong Safety Cultures in Colleges and Universities. Journal of Chemical Health and Safety, 20, 27-34. https://doi.org/10.1016/j.jchas.2013.06.011

[18] Johnson, R.T. and Dickersin, K. (2007) Publication Bias against Negative Results from Clinical Trials: Three of the Seven Deadly Sins. Nature Reviews Neurology, 3, 590. https://doi.org/10.1038/ncpneuro0618

[19] Dirnagl, U. and Lauritzen, M. (2010) Fighting Publication Bias: Introducing the Negative Results Section. Journal of Cerebral Blood Flow and Metabolism, 30, 263-1264. https://doi.org/10.1038/jcbfm.2010.51

[20] Fanelli, D. (2012) Negative Results Are Disappearing from Most Disciplines and Countries. Scientometrics, 90, 891-904. https://doi.org/10.1007/s11192-011-0494-7 